\title{
Research on the Correlation Between Intelligence Level and Psychological Indicators of College Students
}

\author{
Jianlong Qian \\ Physical Education College of Jianghan University, Wuhan, Hubei, China \\ qjijcg@126.com
}

Keywords: Intelligence, Psychological Indicators, Correlation

\begin{abstract}
In this paper, 32 college students from the physical and non physical education major of Jianghan University are studied. The research methods of literature, questionnaire, experiment and psychological measurement are used to study the correlation of mental indicators of College Students' intelligence level and action stability, reaction time, attention and so on. The purpose of this study is to clarify the correlation between intelligence and stability, reaction time, attention and other psychological indicators, so as to provide a theoretical basis for psychological quality. The results show that intelligence is significantly correlated with several psychological indicators, and the intelligence level of sports majors is significantly correlated with these indicators.
\end{abstract}

\section{大学生智力水平与几项心理指标的相关关系研究一一以江汉大学 32 名大学生实验对象 钱建龙 \\ 江汉大学体育学院, 武汉, 湖北, 中国 qjljcg@126.com}

关键词：智力，心理指标，相关关系

摘要：本文以江汉大学体育专业与非体育专业的 32 名同学为研究对象, 采用文献资料、问卷 调查、实验、心理测量等研究方法, 对大学生智力水平与与动作稳定性、反应时、注意力等几 项心理指标的相关性进行研究。旨在厘清智力与动作稳定性、反应时、注意力有密切的相关关 系。研究结果表明: 智力与几项心理指标存在显著相关, 体育专业学生的智力水平与这几项心 理指标的相关性更明显。

\section{1. 前言}

认知和情绪是人的两种重要的心理活动, 认知是情绪重要的基础, 情绪对认知也有一定的 影响。因此研究智力水平对大学生和心理学理论有十分重要的意义。有研究表明: 运动员的智 力发展水平与文理科大学生的智力发展水平无显著性差异, 体育训练同科学文化知识学习一 样，都对智力的发展起到促进作用。那么智力同反应时、动作稳定性、注意力这几项经常使用 的心理指标有没有一定的相关关系呢？这是本文要研究的主要问题。

本论文对江汉大学体育专业与非体育专业共 32 名学生进行了心理测试及实验研究, 主要研 究大学生的心理指标中的反应时、动作稳定性、注意力与智力的相关关系。通过本次实验研究, 如果可以发现这几类心理指标间的相关关系, 那么对运动心理理论研究及运动实践都有十分重 要的指导意义。 


\section{2. 研究对象与方法}

\section{1 研究对象}

选取江汉大学体育专业与非体育专业 2 个类别的学生共计 32 人, 其中体育专业是由体育教 育专业大一、大四学生组成, 每个年级男生女生各四名; 非体育专业由公共管理系的 16 名学 生组成。研究对象基本情况见表 1 。由表 1 对比分析, 我们发现体育专业与非体育专业的学生 智力水平在非常优秀的范围且不存在差异（成人标准智力测量量表规定 IQ 分值在 120 140 间 是智力非常优秀）。

表 1 本文研究对象基本情况一览表

\begin{tabular}{cccc}
\hline & 人数 $(\mathrm{n})$ & 年龄 $(\bar{x})$ & 智力分值 $(\bar{x})$ \\
\hline 体育专业 & 16 & 21.3 & 124.8 \\
非体育专业 & 16 & 21.7 & 128.5 \\
\hline
\end{tabular}

\section{2 研究方法}

1）文献资料法

查阅国内外运动心理学、普通心理学、运动训练学等学科有关方面的纸质文献资料及电子 信息资源，进行选题、论证、研究设计及论文撰写。

2) 心理测量法

采用成人标准智力测量量表, 对江汉大学 32 名学生进行智力测试, 发放 32 份智力测量量 表，收回 31 份。回收率 $97 \%$

3）心理实验法

\section{A 实验仪器}

华东师范大学科教仪器厂生产的 EP701C一注意力集中性测试仪, EP711一双手调节器, EP206一反应时测试仪, 计时器, 秒表等。

B 实验程序

实验程序为: 首先对所有被试进行智力测试，测试时严格按照标准智力测试量表要求，在 规定时间内完成。然后进行测试动作稳定性、反应时、注意力的实验操作。进行实验操作前向 被试说明实验的具体操作方法，并做预备性实验直至被试熟悉实验全过程。进行实验操作前要 求被试处于安静状态下，心率在 70 80 次/每分间，每组实验做三次取平均值，记录实验完成时 间及出错次数。实验全过程保证实验条件一致，避免外界干扰或环境影响。实验完成后记录原 始数据。

4) 数理统计法

主要采用 SPSS 统计软件进行数据处理, 采用 Kendall's tau-b, Spearman 系统作出相关分析。

\section{3. 研究结果与分析}

\section{1 全体被试智力与各心理指标的相关}

研究结果显示：智力与动作稳定性呈显著负相关，智力同注意力集中性呈正相关，智力与 反应时呈负相关，（见表 2）。表明智力水平越高动作控制能力反而越底。智力水平高的学生 注意力会越专注，智力水平越高被试完成实验所需的时间越少。 
表 2 智力 $(\mathrm{n}=31)$ 同三项心理指标 $(\mathrm{n}=93)$ 的相关关系

智力水平

\begin{tabular}{ccc}
\hline & $\mathrm{r}$ & $\mathrm{P}$ \\
动作稳定性 & -0.954 & $\mathrm{P}<0.05$ \\
注意力 & 0.725 & $\mathrm{P}<0.05$ \\
反应时 & -0.809 & $\mathrm{P}<0.05$ \\
\hline
\end{tabular}

\section{2 体育专业与非体育专业学生智力与几项心理指标的相关性比较}

研究发现，体育专业与非体育专业间智力水平与三项心理指标的关系有显著差异。（见表 3 ) 有研究表明参与锻炼人群的选择反应时要短于不锻炼的人群, 差异具有非常显著性 $(\mathrm{P}<$ 0.001 ）。在智力与动作稳定性相关性方面, 体育专业生与非体育专业学生存在一定的差异。据 此认为体育专业的学生在运动训练的作用下各项运动能力得到很好的发展, 对肢体有较好的控 制能力, 在这个因素的影响下, 体育专业的学生在智力与动作稳定性实验中才会表现出二者有 高度的相关, 而非体育专业学生智力水平与动作稳定性显得差一些。其原因在于体育专业的学 生通过多方面的运动训练使动作灵敏素质、反应素质动作协调性等方面得到很好的锻炼。所以 动作稳定性受到了智力与运动训练的双重影响。

研究结果还发现，体育专业学生与非体育专业学生智力与注意力集中性实验完成时间呈负 相关性也存在差异。由此可以发现智商越高, 完成注意力集中性实验的所需时间越短; 说明智 力水平高的学生对刺激物能快速作出反应, 对刺激信号的专注程度很高反应非常灵敏, 注意力 集中性水平能维持较长的时间; 同时在体育运动训练的影响下, 体育专业学生对肢体控制能力, 动作操作能力水平较一般人能力更高, 在智育和体育的双重因素作用下体育专业学生完成注意 力集中性实验的时间更短。体育专业学生智力水平高, 完成注意力集中性实验的时间短, 实验 结果表明智力与注意力有显著的相关性。比较智力与注意力间的结果可以发现智力水平的高低 对注意力的影响很大，可以说智商高的人自我控制力、注意力集中性更强。

在实验心理学研究中，反应时常被用于注意力的评价。因为反应时与准备阶段的心理定向 密切相关, 在很大程度上反映了被试注意力的水平。与此同时, 在本次实验中我们发现了智力 因素与反应时、注意力二者的密切相关性。体育锻炼对反应时、注意力的训练能使这两项指标 水平有很大的提高, 这一点在很多研究中都得到过验证, 是勿庸质疑的。由于本实验表明智力 与注意力、动作稳定性的显著相关，所以在运动训练的作用下提高注意力、反应时的水平在很 大程度上对智力的发展起着积极的作用。

表 3 体育专业与非体育专业大学生几项心理指标相关性的比较 $(n=32)$

\begin{tabular}{lccccc}
\hline & 智力与动作稳定性 & \multicolumn{2}{c}{ 智力与注意力 } & \multicolumn{2}{c}{ 智力与反应时 } \\
& $\mathrm{r}$ & $\mathrm{p}$ & $\mathrm{r}$ & $\mathrm{p}$ & $\mathrm{r}$ \\
\hline 体育专业 $(\mathrm{n}=16)$ & -0.64 & $\mathrm{P}<0.05$ & $-0.447 \mathrm{P}>0.05$ & $0.722 \mathrm{P}<0.05$ \\
非体育专业 $(\mathrm{n}=16)$ & $-0.365 \mathrm{P}>0.05$ & $0.239 \mathrm{P}>0.05$ & $0.853 \mathrm{P}<0.05$ \\
\hline
\end{tabular}

\section{3 体育与非体育专业智力与实验出错次数比较}

对比分析体育专业与非体育专业学生实验出错次数（见表 4) 可以发现非体育专业学生的 智力与三项实验出错次数显著相关, 但是体育专业学生相关性相较而言不是那么明显。在体育 锻炼的作用下体育专业学生实验出错率要低与非体育专业学生, 说明学生出错情况受到了体育 
锻炼的影响。体育锻炼对智力有积极的影响。智力受到体育与智育双因素的作用。

通过体育专业与非体育专业心理实验出错次数对比分析, 可以得出这样的一个结论: 动作 稳定性与智力高度相关, 体育专业学生的动作稳定性水平明显高于非体育专业的学生, 反应时、 注意力能力的高低与智力具有一定的相关性。

分析体育专业与非体育专业智力与其他三项运动心理指标相关关系时发现：非体育专业学 生三项运动心理指标出错情况与智力的相关性要高与非体育专业的学生, 可以认为由于锻炼的 影响使体育专业学生对肢体的控制能力更强, 对思维的动作表达更为清晰明确。运动训练与智 力有密切关系, 尤其是与动作稳定性、注意力、反应时有关的锻炼更能对智力有积极的影响。

表 4 体育专业与非体育专业学生各项指标对比一览表

\begin{tabular}{|c|c|c|c|c|c|c|}
\hline & \multicolumn{2}{|c|}{$\begin{array}{c}\text { 智力与动作稳定性实验出错 } \\
\text { 次数 }\end{array}$} & \multicolumn{2}{|c|}{$\begin{array}{c}\text { 智力与注意力脱靶次 } \\
\text { 数 }\end{array}$} & \multicolumn{2}{|c|}{$\begin{array}{c}\text { 智力与反应时出错次 } \\
\text { 数 }\end{array}$} \\
\hline & $\mathrm{r}$ & $\mathrm{p}$ & $\mathrm{r}$ & $\mathrm{p}$ & $r$ & $\mathrm{p}$ \\
\hline 体育专业 & -0.959 & $\mathrm{P}<0.05$ & -0.388 & $\mathrm{P}>0.05$ & 0.423 & $\mathrm{P}>0.05$ \\
\hline 非体育专业 & 0.615 & $\mathrm{P}<0.05$ & -0.524 & $\mathrm{P}<0.05$ & -0.091 & $\mathrm{P}<0.05$ \\
\hline
\end{tabular}

\section{4. 结论与建议}

\section{1 结论}

智力与动作稳定性、注意力、反应时这三项运动生理指标存在显著相关。且体育专业学生的 相关性更为显著与。

\section{2 建议}

1）学校需要加强体育活动内容, 以此来促进智力和动作稳定性、注意力、反应时等三项心理 能力的发展。

2）文化知识和运动知识教育应 “双管齐下”，才能更好地提高智力水平。

一般情况下，教育部门主要通过文化学习的方法来提高学生智力水平。通过本文的研究发 现动作稳定性、注意力、反应时与智力水平显著相关, 利用运动训练提高智力水平此种方法往 往被忽视, 现在研究证明动作稳定性、注意力、反应时这三项心理指标可以提高智力水平，那 么体育锻炼作为一种提高学生智力水平的方法是可行的。通过体育锻炼, 提高智力的同时舒缓 压力, 是实行素质教育的可行方法。

3）重视动作稳定性、注意力、反应时等三项心理指标的发展, 以此来提高智力水平，促进情 商的发展。

智力与三项运动生理指标关系密切, 相互影响, 作为高素质的体育专业人才有意识的提高 知识能力水平，激活思维，开发智力同样能提高竞技技术水平，促进竞技能力的提升。学习的 同时不忘体育锻炼不但能对智力起到积极的影响，还能增进健康，增强体质，提高运动技术能 力。让体力同智力共同发展, 为成为高素质有能力的人才做准备。

\section{参考文献}

[1] 斯腾伯格(Sternberg,R.J.), 威廉姆斯(Williams,W.M.).教育心理学[M].北京:中国轻工业出版社, 2003, 22-25.

[2] 莫雷.心理学[M].广州:广东高等教育出版社, 2017, 244.

[3] 祝蓓里, 季浏.体育心理学[M].北京:高等教育出版社, 2018, 68.

[4] 郭可教, 雷庆文, 罗敏.学生智力与反映时的关系的教育神经心理学研究 [J].心理科学.1995, (18):149-152. 
[5] 宋和平，张西渭。体育运动与智力发展[J].渭南师专学报.1997, (2):57.

[6] 马锋，郭永波. 体育教学过程中的智力培养[J].北京体育大学学报.2012, (25):675-676.

[7] 黄白.智力结构理论新研究述要[J].河池师专学报.2012, (4):43.

[8] 徐文.论体育运动与智力因素的关系[J].武汉体育学院学报.1998, (1):99.

[9] 谢国栋.评价运动员的智力及智力测验问题[J].广东体育学院院报.2012, (2):50.

[10] 严进洪.反应时与动作速度精确度之关系[J].体育科学.2001, (1):66.

[11] 张雁.反应时测试的应用[J].中国康复理论与实践.2015, (11):34.

[12] 张亚.我国成年人选择反应时状况分析[J].天津体育学院学报, 2006, (05).

[13] 黄希庭.运动心理学[M].上海:华东师范大学出版社, 2015. 